\section{Segurança alimentar de migrantes e refugiados: um desafio bioético}

\section{Elero, Yasmin}

Bacharel em Direito e Nutricionista, mestranda Programa de Pós-graduação em Bioética da Pontifícia Universidade Católica do Paraná. Escola Ciências da Vida. yasminelero@gmail.com

\section{Rosaneli, Caroline Filla}

Pós-doutora em Bioética pela Universidade de Brasília. Pontifícia Universidade Católica do Paraná. Escola Ciências da Vida. Programa de Pós-graduação em Bioética. Grupo de Pesquisa Bioética, Saúde Pública e Direitos Humanos

\section{Rocha, Anna Silvia Penteado Setti da}

Universidade Tecnológica Federal do Paraná. Grupo de Pesquisa Bioética, Saúde Pública e Direitos Humanos

\section{Friedrich, Tatyana Scheila}

Universidade Federal do Paraná. Programa de Pósgraduação em Direito. Programa Política Migratória e Universidade Brasileira. Projeto Refúgio, Migrações $e$ Hospitalidade.

\section{Cruz, Jasmine Salua Dutra Ephigenio da}

Pontifícia Universidade Católica do Paraná. Escola Ciências da Vida. Programa de Pós-graduação em Bioética. Grupo de Pesquisa Bioética, Saúde Pública e Direitos Humanos

\section{Cunha, Thiago Rocha da}

Pontifícia Universidade Católica do Paraná. Escola Ciências da Vida. Programa de Pós-graduação em Bioética. Grupo de Pesquisa Bioética, Saúde Pública e Direitos Humanos

PALAVRAS-CHAVE: Migração, Direitos Humanos, Fome, Bioética.

Esta comunicação tem como objetivo discutir a segurança alimentar e nutricional dos migrantes e refugiados enquanto uma problemática persistente na interface entre a bioética e os direitos humanos. Nesse sentido, a alimentação é compreendida como uma questão fundamental à manutenção da vida humana, tanto em relação aos aspectos objetivos, implicados, sobretudo, nas condições de saúde, quanto aos aspectos subjetivos, implicados à cultura e às relações sociais. Por isso, ao analisar a problemática da segurança alimentar, deve-se considerar as barreiras adicionais que são enfrentadas nos processos migratórios. $\mathrm{Na}$ perspectiva da pluralidade moral e da interdisciplinaridade, este trabalho buscou um diálogo entre a chamada Bioética Social, caracterizada sobretudo pelas abordagens da Bioética de Intervenção e a Declaração Universal sobre Bioética e Direitos Humanos. A partir desta ótica, algumas barreiras se destacaram, como situação social de pobreza, exclusão, preconceito, pouca variedade de alimentos, dificuldade de acesso e ausência total de direitos, ou seja, problemas estruturais associados a diversas limitações quando examinados em conjunto, definem diferentes configurações de vulnerabilidades dos migrantes e refugiados. Frente ao problema, e tendo como base o arcabouço teórico-normativo, algumas estratégias de enfrentamento foram estabelecidas, como a economia solidária envolvendo grupos de migrantes e refugiados, o fomento a bancos de alimentos para situações de crises, mas, sobretudo, por meio da intervenção por meio de processos políticos que estabeleçam uma cultura alimentar segura que promova a conectividade social e física ao mesmo tempo em que ataca as causas estruturais da fome e da exclusão, sobretudo no que se refere ao desemprego e ao subemprego dos migrantes e refugiados. Nesse sentido, entende-se que o Estado tem o dever de criar medidas necessárias para diminuir o impacto da fome e a má nutrição visando à realização dos direitos humanos de toda a coletividade. Promover a equidade social com relação aos grupos vulneráveis e excluídos da sociedade ainda é um desafio, e quando o cenário se trata de migrantes e refugiados as barreiras inerentes a essa condição, sejam elas relacionadas ao idioma, à cultura ou às tradições, tornam o problema ainda mais grave. É imperativo, por isso, a introdução de políticas públicas orientadas pela interface entre a Bioética e Direitos Humanos que estimulem a emancipação dos grupos citados, para que esses rompam definitivamente o ciclo de exclusão e dependência que marcam a sua vulnerabilidade.

\section{REFERÊNCIAS}

[1] CARVAlHO, L.R.T., ROCHA, D.G. Programa de Aquisição de Alimentos: a lente bioética na segurança alimentar. Rev Bioét. 2013;21(2):278-290.

[2] GARRAFA, V. and D. PORTO (2002). "Bioética, poder e injustiça: por uma ética de intervençäo." Mundo Saúde 26(1): 6-15.

[3] HAMMELMAN, C. Investigating connectivity in the urban food landscapes of migrant women facing food insecurity in Washington, DC. Health and Place, 2018.

[4] MCKAY, F. H.; DUNN, M. Food security among asylum seekers in Melbourne. Australian and New Zealand Journal of Public Health, 2015.

[5] WALSEMANN, K. M.; RO, A.; GEE, G. C. Trends in food insecurity among California residents from 2001 to 